\title{
DESIGUALDADE DE GÊNERO E MEDIÇÃO JUDICIAL EM DIVÓRCIO'
}

\author{
INEQUALITY OF GENDER AND DIVORCE JUDICIAL MEDIATION
}

\author{
Larissa Fernanda Romão da Cunha*
}

\begin{abstract}
Resumo:
O estudo apresentado é fruto de uma pesquisa de caráter interdisciplinar, que busca enxergar o Direito e, principalmente, os métodos consensuais de solução de conflitos, sob lentes antropológicas e feministas. A metodologia utilizada foi qualitativa. A partir de uma perspectiva etnográfica, e da premissa de que a sociedade atual tem bases patriarcais, buscou-se investigar de que forma a desigualdade de gênero é absorvida em mediações/conciliações judiciais de divórcio que ocorrem no CEJUSC da Vergueiro. A hipótese a ser verificada no desenvolver da pesquisa era a de que, em função da desigualdade de gênero existente e da informalidade inerente aos meios de conciliação/mediação, estereótipos de gênero impactam nos resultados. Para tanto, buscou-se, inicialmente, estabelecer uma conexão entre a importância em se pensar os métodos consensuais de solução de conflitos, tendo em vista o recente e notável destaque do tema na legislação brasileira, sob uma perspectiva feminista, a fim de viabilizar uma busca por um acesso à justiça efetivo. Em seguida, por meio, principalmente, de transcrições de narrativas consolidadas no Caderno de Campo, bem como da obra de Trina Grillo, analisou-se o dia a dia do CEJUSC da Vergueiro e as sessões de mediação/conciliação em matéria de divórcio que nele ocorreram.

Palavras-chave: Desigualdade de Gênero. Mediação. Divórcio. CEJUSC. Acesso à Justiça. Antropologia do Direito.
\end{abstract}

\begin{abstract}
:
The study presented is the result of an interdisciplinary research which seeks to see the Law and, mainly, the consensual conflict resolution methods, under anthropological and feminist lenses. The methodology used was qualitative. From an ethnographic perspective, and from the premise that today's society has a patriarchal basis, I sought to investigate how gender inequality is absorbed in judicial divorce mediations/conciliations that occur in the Vergueiro CEJUSC. The hypothesis to be verified in the development of the research was that, due to the existing gender inequality and the informality inherent in the means of conciliation / mediation, gender stereotypes impact on the results. In order to do so, I initially sought to establish a connection between the importance of considering consensual conflict resolution methods, in view of the recent and notable mention of the topic in Brazilian laws, from a feminist perspective in order to enable a search for an access
\end{abstract}

1 Este artigo apresenta os principais pontos abordados em minha tese de láurea, que foi aprovada em 27.11.2018 e recebeu indicação ao "Prêmio Jovem Jurista". Agradeço imensamente à Prof. ${ }^{a}$ Susana Henriques da Costa, minha orientadora, que é uma mulher fortaleza em meio a um exército de homens e que conseguiu fazer acender meu coração, e à Prof. ${ }^{a}$ Maria Cecília de Araújo Asperti, membra da minha banca, que foi uma luz guia do começo ao fim deste trabalho.

* Bacharel em Direito pela Faculdade de Direito da Universidade de São Paulo. 
to effective justice. Then, through mainly transcripts of narratives consolidated in the Field Diary, as well as the Trina Grillo's work, I analyzed the day-to-day of the CEJUSC of Vergueiro and mediation/conciliation sessions on divorce occurring in it.

Keywords: Gender Inequality. Mediation. Divorce. CEJUSC. Access to justice. Anthropology of Law.

Introdução

Para melhor compreensão da pergunta de partida e da hipótese deste trabalho, primeiro se esclarecerá alguns conceitos. A pergunta de partida é: "De que forma a desigualdade de gênero é absorvida em mediações/conciliações judiciais de divórcio que ocorrem no CEJUSC da Vergueiro?", partindo-se da premissa de que há uma desigualdade de gênero posta hoje em decorrência de uma sociedade com alicerces patriarcais.

O termo "patriarcado" é produto da combinação das palavras gregas pater (pai) e arkhe (origem e comando) e, no sentido feminista e contemporâneo, designa uma formação social em que o homem detém a autoridade. Assim, é um conceito que pretende descrever um sistema total que comanda o conjunto das atividades humanas, coletivas e individuais (DELPHY, 2009, p. 174-178).

Nessa toada, sob uma perspectiva de uma sociedade regida pelo modo de produção capitalista, possível dizer que há uma absorção retardada - e nunca plenamente realizada (já que todo modo de produção é um fenômeno histórico, que se transforma com o tempo) - de determinados contingentes populacionais pelas relações de produção típicas das sociedades capitalistas (SAFFIOTI, 2013, p. 58).

Outrossim, fatores de ordem natural, por exemplo, de sexo e raça, operam como válvulas de escape para aliviar, de forma aparente, as tensões sociais geradas pelo modo capitalista de produção. Ou seja, muda-se o foco de atenção da estrutura de classes para características físicas que, naturalmente, certas categorias sociais possuem, de modo que a manutenção das minorias políticas atua como mecanismo auxiliador da realização histórica do sistema capitalista de produção (SAFFIOTI, 2013). Assim, o desvio do foco de atenção da estrutura de classes para determinados setores demográficos que carregam certos caracteres naturais impossíveis de anulação é necessário para que o trabalhador permaneça oferecendo sua força de trabalho como mercadoria, o que é condição para o surgimento do capital, bem como aceitando a divisão social do trabalho e as hierarquias de classe (SAFFIOTI, 2013).

Vale dizer, ainda, que, com o decorrer do tempo, o sistema capitalista tem se revelado maleável, permitindo e, em alguns casos, estimulando mudanças institucionais de modo a, aparentemente, inserir no sistema produtivo categorias sociais tradicionalmente 
alijadas (SAFFIOTI, 2013, p. 61). Nesse sentido, por exemplo, possível mencionar o sufrágio universal e o assalariamento das mulheres.

Faz-se a ressalva de que as mulheres das camadas sociais diretamente ocupadas na produção de bens e serviços nunca foram alheias ao trabalho, pois sempre foram compelidas a contribuir para a subsistência da família em que estavam inseridas e para a criação da riqueza social. Contudo, o modo de produção capitalista marginaliza progressivamente - e ainda mais - as mulheres das funções produtivas, apenas inserindoas em um processo de assalariamento em função do intenso movimento de urbanização e da revolução industrial, ou seja, a fim de obter-se mais lucro (SAFFIOTI, 2013).

Assim, a manutenção das minorias políticas serve também para aumentar o lucro da classe burguesa. As mulheres, por exemplo, ao serem assimiladas pelo sistema produtivo, são muito mais exploradas, delas é arrancado o máximo da mais-valia absoluta através da intensificação do trabalho, da extensão da jornada de trabalho e de salários mais baixos que os masculinos ${ }^{2}$ (SAFFIOTI, 2013, p. 67).

Tal elasticidade trata-se, em verdade, de soluções pensadas para problemas gerados pelo próprio sistema capitalista, sendo que tais "soluções" encontram limites no próprio capital. Desse modo, cabe questionar se, a tais categorias sociais, pode o sistema capitalista de produção, de fato, oferecer plenas possibilidades de integração social (SAFFIOTI, 2013).

Nessa toada, o Direito burguês surge como atributo exigido para o processamento do intercâmbio comercial, para que mercadorias possam ser compradas e vendidas, mas, principalmente, para que o trabalhador possa vender a si mesmo, sua própria força de trabalho. Assim, a forma-sujeito se constitui não somente para possibilitar um circuito de trocas mercantis, mas, também, para que possa circular a mercadoria trabalho (NAVES, 2017, p. 18).

Para tanto, necessário que a subjetividade humana adquira uma forma específica irredutível. O homem (e esse termo, usado como sinônimo de pessoas, não é algo desproposital), então, precisa ser livre, dotado de uma autonomia da vontade que o habilite para os atos da vida civil, igual a todos os outros homens, de modo a permitir uma relação de troca equivalente, e precisa ser proprietário, dispor do que é seu. Isso tudo, porém, apenas no plano da legalidade jurídica, resultando na figura do sujeito neutro de direito (NAVES, 2017). A mulher, assim, adentra a esse contexto como mero instrumento de produção (SAFFIOTI, 2013, p. 117), como categoria social alijada, como ferramenta de geração de maior lucro. Por isso, o Direito burguês foi criado por homens detentores do poder e em benefício destes.

Esse cenário, inclusive, permanece até os dias de hoje, como demonstra pesquisa do IBGE (PERET, 2018). 
Nesse sentido, objetivando fortalecer a desigualdade entre homens e mulheres, como se esta significasse que aquela categoria é superior à esta, ocorre a chamada "socialização", que é, basicamente, a educação transmitida da geração mais velha para a mais nova em relação aos modos de comportamento exigidos pela sociedade conforme o seu gênero. Sobre isso, aduz Saffioti (2013, p. 121):

O domínio exercido pela geração madura sobre a geração imatura vincula-se à necessidade social de introjetar nos mais jovens os conteúdos da cultura vigente na sociedade, tomando-se a cultura quer enquanto a fornecedora dos elementos padronizados de interação social, quer enquanto o resultado operante de formas de ajustamento do homem à natureza que o circunda.

Um dos produtos da socialização é a criação dos chamados estereótipos de gênero. Estereótipo, de acordo com o Dicionário Michaelis, ${ }^{3}$ pode ser definido como "Imagem, ideia que categoriza alguém ou algo com base apenas em falsas generalizações, expectativas e hábitos de julgamento". Assim, estereótipo de gênero pode ser entendido como uma imagem criada socialmente acerca do que significa ser mulher e homem.

A hipótese deste trabalho é a de que, em função da desigualdade de gênero existente e da informalidade inerente aos meios de conciliação/mediação, estereótipos de gênero impactam nos resultados.

Por sua vez, quanto à informalidade presente nos meios alternativos de solução de disputas, esta aparece como um dos seus princípios norteadores no art. $2^{\circ}, I V^{4}$ da Lei n. 13.140/2015, bem como no art. 166, caput $^{5}$ do CPC/2015. A lógica é a de que não recaia sobre esses métodos diretrizes inflexíveis de condução do procedimento, o qual se guiará pela livre determinação do mediador e dos mediandos. Assim, tudo dependerá das escolhas (ou da ausência de escolhas) das partes ali envolvidas.

Já são vários os estudos que buscam investigar o papel dos estereótipos de gênero em decisões judiciais. ${ }^{6}$ Contudo, no meio dos métodos alternativos de resolução de conflitos, esse tipo de estudo é ainda incipiente. O estudo mais aprofundado neste tópico que foi encontrado e usado como marco teórico neste trabalho foi o de Trina Grillo, escrito

3 ESTEREÓTIPO. In: MICHAELIS: dicionário brasileiro da língua brasileira. São Paulo: Melhoramentos. Disponível em: https://michaelis.uol.com.br/moderno-portugues/busca/portugues-brasileiro/ estere\%C3\%B3tipo/. Acesso em: 1 ago. 2018.

4 Art. $2^{\circ} \mathrm{A}$ mediação será orientada pelos seguintes princípios:

IV - informalidade;

5 Art. 166. A conciliação e a mediação são informadas pelos princípios da independência, da imparcialidade, da autonomia da vontade, da confidencialidade, da oralidade, da informalidade e da decisão informada.

6 Possível citar, à título de exemplo, as seguintes obras: Asperti, (2017); PANDJIARJIAN, ([2003?]) e Cava (1990). 
em 1991, nos Estados Unidos. Assim, é de grande importância que esse estudo aconteça no Brasil atual.

Quanto à metodologia, foi adotada uma observação participante de tipo etnológico, sendo o Caderno de Campo o principal instrumento de pesquisa. Vale dizer que, por tratar-se de ambiente forense, há limitações inerentes que impedem de colocar em prática o método etnológico como originalmente ele foi concebido. Contudo, essa modificação de aplicação do método ocorre, na verdade, em todos os trabalhos de duração limitada. Nestes casos, são aplicados métodos de observação comparáveis, de modo flexível (QUIVY; CAMPENHOUDT, 2005, p. 195-196).

Para demarcar o ponto de vista, optou-se pelo uso da primeira pessoa na escrita, posicionando-se como observadora participante. Tal técnica permite, aliás, o acesso a informações que não seriam disponibilizadas facilmente em uma observação desinteressada (GOODE; HATT, 1960 apud CHIESA; FANTINEL, 2014).

O espaço geográfico escolhido como palco para os estudos deste trabalho foi a Unidade Avançada de Atendimento Judiciário, da Vergueiro, que é um dos Centros Judiciários de Solução de Conflitos e Cidadania de São Paulo, também conhecidos como CEJUSCs.

1. Métodos alternativos de resolução de conflitos e acesso à justiça

De início, necessário discorrer sobre os marcos regulatórios dos métodos consensuais no Brasil. Como bem apresentou Ada Pellegrini Grinover (2015), são três os marcos regulatórios que regem os métodos consensuais no Brasil: (a) a Resolução n. 125/2010 do Conselho Nacional de Justiça (CNJ), que - embora em nível de norma administrativa - instituiu e continua regendo a política nacional dos meios alternativos ${ }^{7}$ de solução de conflitos; (b) os dispositivos do CPC/15; e (c) a Lei n. 13.140/2015. ${ }^{8}$

O movimento de expansão e regulamentação dos meios alternativos de resolução de conflitos não é restrito ao Brasil. Segundo Grinover (2015), nos últimos anos, há um considerável aumento do estudo e da implantação dos institutos dos meios alternativos de resolução de disputas, inclusive no Brasil.

Do ponto de vista do legislador, as motivações para essa mudança legislativa no Brasil podem ser encontradas nas considerações iniciais da Resolução n. 125/2010, do CNJ, sendo algumas delas a busca por: (a) eficiência operacional, acesso ao sistema de

\footnotetext{
7 Originado da expressão em inglês Alternative Dispute Resolution (ADR), é controverso o uso do termo "alternativo". Há doutrinadores que defendem o uso de palavras como "adequado" ou "amigável". Nesse sentido: Lee, (2012).

8 Conhecida como "Lei da Mediação".
} 
Justiça e responsabilidade social; (b) organização, em âmbito nacional, dos serviços que possam ser prestados mediante outros mecanismos de solução de conflitos; (c) incentivo e aperfeiçoamento dos mecanismos consensuais de solução de litígios; (d) pacificação social, solução e prevenção de litígios; e (d) redução de excessiva judicialização de conflitos de interesses.

Para Mauro Capelletti e Bryant Garth, a procura de alternativas para resolução de conflitos se insere na chamada "terceira onda" do movimento de acesso à justiça, em que há o reconhecimento de que os conflitos são distintos entre si, bem como os agentes neles envolvidos, motivos pelos quais se faz necessário pensar acerca das melhores soluções às diferentes demandas. Frente a essa situação, a "terceira onda" do movimento de acesso à justiça preocupa-se com a busca por reais alternativas aos juízos ordinários e aos procedimentos usuais, a fim de transpor o obstáculo processual e garantir um acesso a segmentos cada vez maiores da população (CAPPELLETTI; GARTH, 1988; CAPPELLETTI, 1994).

Percebe-se que Mauro Capelletti e Bryant Garth entendem que a procura de alternativas para resolução de conflitos caminha no sentido da busca por um acesso à justiça universal. Para tanto, partem do princípio de que a expressão "acesso à justiça":

\section{[...] é reconhecidamente de difícil definição, mas serve para determinar duas finalidades básicas do sistema jurídico - o sistema pelo qual as pessoas podem reivindicar seus direitos e/ou resolver seus litígios sob os auspícios do Estado. Primeiro, o sistema deve ser igualmente acessível a todos; segundo, ele deve produzir resultados que sejam individual e socialmente justos. Nosso enfoque, aqui, será primordialmente sobre o primeiro aspecto, mas não poderemos perder de vista o segundo. Sem dúvida, uma premissa básica será a de que a justiça social, tal como desejada por nossas sociedades modernas, pressupõe o acesso efetivo. (CAPPELLETTI; GARTH, 1988, p. 8, grifo nosso).}

É preciso, contudo, fazer algumas ressalvas quanto ao estudo, na atualidade, do trabalho de Mauro Capelletti e Bryant Garth, o qual fornece alicerces para este trabalho de conclusão de curso.

Não se passa despercebido que a origem do trabalho de Mauro Capelletti e Bryant Garth se deu em outro contexto histórico e social e não pode ser simplesmente transportado para a atualidade e realidade brasileira sem algumas reflexões.

A concepção de universalização da justiça assumida pelos autores se deu sob a esperança do Estado de bem-estar social, o qual não passou de uma promessa vazia no Brasil. O estabelecimento do Estado neoliberal no Brasil, nos anos 80/90, influenciou as reformas políticas e legislativas advindas com a Constituição Federal de 1988 
(GABBAY; ASPERTI; COSTA, 2017). Assim, importante esclarecer que este trabalho não considerará o conceito de acesso à justiça como sinônimo de acesso universal, ou seja, por todos os cidadãos, ao sistema de justiça, mas sim como um direito, que, para sua efetivação, demanda a implementação de políticas públicas e depende de recursos limitados (GABBAY; ASPERTI; COSTA, 2017). ${ }^{9}$

Além disso, um acesso à justiça efetivo se realiza quando não se nega que a sociedade atual é composta por diferentes sujeitos, sobre os quais recai uma estrutura que impõe desigualdades. Neste estudo, pretende-se chamar a atenção para a diferente experimentação do sistema de justiça por homens e mulheres, buscando entender de que forma a desigualdade de gênero, decorrente de uma sociedade patriarcal, é absorvida em mediações/conciliações judiciais de divórcio.

Desse modo, este trabalho direciona-se pela segunda finalidade do sistema jurídico antes mencionada, ou seja, a produção de resultados que sejam individual e socialmente justos.

Outrossim, retomando a ideia de que a procura de alternativas para resolução de conflitos se insere no que Capelletti e Garth denominaram "terceira onda" no movimento de acesso à justiça, em relatório de abertura do Simpósio Jurídico W. G. Hart sobre a Justiça Civil e suas alternativas, realizado em Londres, no Institute of Legal Advanced Studies, em 1992, Capelletti discorre sobre o assunto.

Não obstante elenque os pontos positivos para fortalecer as razões que o fazem considerar que a justiça conciliatória é um passo adiante no acesso à justiça, defendendo os métodos alternativos, Capelletti não se esquiva das críticas levantadas e das possíveis dificuldades que possam ser encontradas com a aplicação destes.

2. Um olhar feminista sobre os métodos alternativos de resolução de conflitos

Cappelletti aponta expressamente o posicionamento da Prof. ${ }^{a}$ Carrie Menkel-Meadow, ${ }^{10}$ ventilado através de resenha publicada em 1986. Segundo a professora (MENKEL-MEADOW, 1986, p. 302 apud CAPPELLETTI, 1994, p. 91), tem havido "crescentes críticas da mediação por parte de hostes feministas, onde se afirma que pessoas de poder desigual tendem a tratar-se reciprocamente mal em procedimentos informais".

$9 \quad$ Nesse sentido: Mendes (2015).

10 Carrie Menkel-Meadow atua, leciona e possui vasta produção acadêmica na área dos métodos alternativos de resolução de disputas desde meados dos anos 1980, sendo, desse modo, uma das primeiras intelectuais do ramo. Destaca-se, ainda, no estudo da ética legal, educação jurídica clínica, teoria jurídica feminista e resolução internacional de conflitos. Atualmente é professora de Direito e Ciências Sociais da Universidade da Califórnia, nos Estados Unidos. 
Em 1997, Menkel-Meadow (1997) afirmou que os dias românticos do movimento das $\mathrm{ADRs}^{11}$ aparentavam ter chegado ao fim. Já na época, a autora identificou alguns problemas que desvirtuariam as proposições iniciais dos métodos alternativos de solução de disputas.

Um desses problemas se dá quando, por exemplo, uma solução é sugerida ou imposta de modo coercitivo às partes pelo facilitador, a "terceira parte neutra". Esta situação seria decorrência do fato de que os indivíduos envolvidos em uma mediação/ conciliação, particularmente o facilitador e o advogado, não estão sabendo agir em conformidade com seus respectivos papéis. A razão para tal pode ser a excessiva informalidade, ou ainda a ausência de ética, padrões de práticas e regras próprias para o meio das ADRs.

Esse cenário decorreria dos persistentes reflexos da cultura do modelo contencioso no meio das ADRs. Ocorre que as regras deste modelo são incompatíveis com a lógica das ADRs, em que há a intenção de uma diferente condução do conflito, pelo modo como se dá a comunicação e a análise dos problemas, bem como de diferentes resultados, ou seja, não necessariamente um ganha-perde, como no modelo contencioso, mas soluções mais complexas e compatíveis com os problemas legais e sociais (MENKELMEADOW, 2000).

Menkel-Meadow (2000), ainda neste sentido, explica que o mundo jurídico passa por um processo de transição cultural, já que há novas abordagens em relação à resolução de conflitos que requerem uma nova "ética" do mundo jurídico e de seus operadores. Isso porque há uma progressiva mudança de foco sobre o que significa chegar a um resultado satisfatório ao se encarar um conflito de interesses entre pessoas. Desse modo, em vez de a maior importância recair sobre quem venceu a disputa, deverse-á privilegiar saber como se deu o processo de resolução daquela disputa. Assim, por exemplo, deverá haver uma preocupação sobre se as partes se sentiram satisfeitas, se houve colaboração entre elas e se houve empoderamento. ${ }^{12}$

Há, desse modo, um aparente desvirtuamento dos propósitos iniciais do movimento das ADRs, o que pode representar um grande risco às partes envolvidas, ante a informalidade dos métodos, principalmente quando há enorme disparidade de armas entre as partes ou simplesmente quando envolve indivíduos com pouco acesso à informação.

${ }^{11}$ Originado da expressão em inglês Alternative Dispute Resolution (ADR). Em português, significa "meios alternativos de resolução de conflitos". Ambas as formas (em inglês e português) serão utilizadas nesse trabalho com o mesmo propósito. O uso da expressão "ADR" justifica-se pela maior facilidade da abreviatura.

12 O uso da expressão "empoderamento", no campo dos métodos alternativos de resolução de disputas, faz referência ao fato de as partes se sentirem capazes de serem as responsáveis por resolverem as suas questões, sem que todo o processo recaia, por exemplo, nas mãos de um advogado ou um juiz. 
Assim, latente a necessidade de se debruçar, por meio de pesquisa empírica, sobre a prática cotidiana dos métodos alternativos de resolução de conflitos, ainda mais ao se considerar a promulgação do "Novo" Código de Processo Civil, em 2015, e seu grande incentivo ao fomento de tais métodos. ${ }^{13}$

Ainda, Menkel-Meadow (1997, p. 412) cita, em nota de rodapé, a obra "The Mediation Alternative: Process Dangers for Women ${ }^{14 "}$, escrita em 1991 por Trina Grillo. ${ }^{15}$ Menkel-Meadow explica brevemente que a obra discute o perigo inerente que processos informais tais quais a mediação podem apresentar em relação aos direitos das mulheres.

No mencionado artigo, Grillo (1991, p. 1.548) explica que seu objetivo é verificar se a mediação obrigatória, em matéria de divórcio, requerida como parte do procedimento judicial, atende às aspirações desse instrumento, ou, em contrapartida, atua apenas como um substituto ao sistema contencioso, sendo igualmente - ou até mais patriarcal e desconsiderando, da mesma forma, as subjetividades dos conflitos (GRILLO, 1991, p. 1.550).

A autora utiliza-se de sua experiência como mediadora e distribui ao longo de seu texto, preservando as identidades das pessoas, descrições de sessões de mediações obrigatórias. Apresenta tanto a perspectiva do mediador, através de descrições de sessões em que ela atuou como mediadora, quanto a perspectiva das partes, através de descrições de sessões em que ela era apenas observadora (GRILLO, 1991). Neste trabalho, utilizouse esse modelo como inspiração.

Primeiramente, importante repisar que o artigo de Trina Grillo (1991) é utilizado como marco teórico por ter sido o estudo encontrado que mais se aproxima da pergunta de partida e hipótese deste trabalho. Assim, serviu de alicerce para este estudo. Contudo, não se pode perder de vista que se trata de um artigo escrito em 1991, no contexto dos Estados Unidos, tendo sido publicado no The Yale Law Journal.

Como já mencionado, a legislação brasileira referente aos métodos consensuais de solução de conflitos é muito recente e a cultura brasileira difere em demasia da estadunidense. Desse modo, não se pode transportar cegamente os apontamentos de Grillo sem localizar-se espacial e temporalmente. Até por isso, é importante a proliferação de mais estudos sobre o tema no Brasil atual, principalmente com embasamento em estudo empírico.

\footnotetext{
13 Nesse sentido: Ostia, (2018).

14 A alternativa da mediação: um processo perigoso para mulheres (tradução nossa).

15 Trina Grillo foi mediadora, pesquisadora e professora em algumas universidades, dentre elas, a University of San Francisco Law School. Destacou-se muito por seu trabalho social, tendo se dedicado a incorporar a diversidade aos estudos jurídicos e produzido notórios trabalhos acadêmicos que trataram acerca de questões pertinentes às minorias sociais.
} 
Dito isto, passa-se a uma segunda observação. Como já mencionado, Grillo diz que seu artigo tem como foco a mediação judicial obrigatória. No art. 334 do Código de Processo Civil brasileiro, a mediação/conciliação judicial foi estipulada como obrigatória, ${ }^{16}$ a não ser que ambas as partes manifestem seu desinteresse ou quando a autocomposição for inadmissível.

No CEJUSC da Vergueiro e em relação às mediações/conciliações de divórcio estudadas nesse trabalho, ${ }^{17}$ todas ocorreram da seguinte maneira: uma das partes procurou a Defensoria Pública, que, ao identificar se tratar de um conflito passível de ser dirimido por meio de um diálogo entre as partes, encaminhava-a ao CEJUSC da Vergueiro, convidando a outra parte a comparecer à sessão.

Caso a escolha da Defensoria Pública e da parte tivesse sido pelo caminho litigioso, do mesmo modo, o juízo designaria a audiência, com exceção das situações já mencionadas. Assim, o cenário atual é o da obrigatoriedade, não obstante as exceções, o que acredita-se ser incompatível com a lógica da mediação/conciliação, que transpassa necessariamente a voluntariedade de ambas as partes. Contudo, esse fator fortalece o uso do artigo de Grillo como marco teórico deste trabalho, apesar do diferente contexto espacial e temporal.

Não bastando, no trabalho de campo, percebe-se ser comum uma incompreensão das partes sobre o que significa uma mediação e uma conciliação, ou seja, geralmente envolve indivíduos com pouco acesso à informação. Além disso, nota-se ser costumeiro que as partes somente entendam como se dará o procedimento no momento de abertura da sessão, com as palavras do mediador - quando elas existem.

06/04/2018: Mediação entre um casal formado por um homem e uma mulher. Na abertura da sessão, no momento em que a mediadora explica como funciona o método, os mediandos dizem que acreditavam que se buscaria em uma conciliação a reconciliação do relacionamento. Achavam que passariam por vários psicólogos, e que estavam preocupados com isso.

16 Art. 334. Se a petição inicial preencher os requisitos essenciais e não for o caso de improcedência liminar do pedido, o juiz designará audiência de conciliação ou de mediação com antecedência mínima de 30 (trinta) dias, devendo ser citado o réu com pelo menos 20 (vinte) dias de antecedência.

$[\ldots]$

$\S 4^{\circ}$ A audiência não será realizada:

I - se ambas as partes manifestarem, expressamente, desinteresse na composição consensual;

II - quando não se admitir a autocomposição.

$\S 5^{\circ} \mathrm{O}$ autor deverá indicar, na petição inicial, seu desinteresse na autocomposição, e o réu deverá fazê-lo, por petição, apresentada com 10 (dez) dias de antecedência, contados da data da audiência.

17 Vale explicar que existe a possibilidade de qualquer pessoa interessada ir diretamente ao CEJUSC para agendar uma sessão de mediação/conciliação. 
Ainda, nota-se que o facilitador presente na audiência geralmente faz uma explicação genérica acerca do que se trata mediação ou conciliação. Imagino que isso ocorra porque, apesar de a mediação ser a técnica mais indicada para relações continuadas e íntimas (como é o caso do divórcio), a praxe do CEJUSC é a realização de conciliações, a não ser que as próprias partes acabem por forçar a realização de uma mediação, ao, por exemplo, suscitar questões mais delicadas que o padrão, e a depender da atitude do próprio facilitador frente a essas questões.

Uma vez esclarecidas as questões sobre a referência espacial e temporal de Grillo e sobre a obrigatoriedade da mediação/conciliação, retorno ao teor do artigo da professora. Trina Grillo aduz que o conceito ocidental de lei está baseado em um paradigma patriarcal, caracterizado pela hierarquia, raciocínio linear, resolução de disputas por meio da aplicação de princípios abstratos e o ideal da pessoa razoável. Assim, há uma clara rejeição às subjetividades de um conflito e uma óbvia separação entre o público e o privado (GRILLO, 1991, p. 1.547).

A autora explica que um paradigma que desconsidere as subjetividades de um conflito é problemático em diversas circunstâncias, mas particularmente quando se trata de um divórcio envolvendo interesse de incapaz, em que a preocupação essencial do Tribunal julgador deve ser o futuro daquela família. Tendo isso em vista, a autora defende que os tribunais não podem ser alvo de confiança nem para produzir apenas resultados nem para tratar os sujeitos com respeito e humanidade. Sendo assim, defende a necessidade de uma reforma do procedimento relativo ao tratamento de casos de divórcio, fazendo a ressalva de que, contudo, qualquer alternativa deve ser capaz de superar qualitativamente o sistema contencioso tradicional, principalmente em relação às pessoas mais vulneráveis na sociedade (GRILLO, 1991).

A autora menciona que uma dessas alternativas que tem despontado com notoriedade é a mediação e passa a discorrer acerca de possíveis qualidades e defeitos de tal instrumento. Quanto às qualidades, Grillo explica que, primeiro, a mediação rejeita uma abordagem que desconsidere as subjetividades envolvidas em um conflito. Além disso, diz que, pelo menos em teoria, a mediação não é coercitiva, mas se propõe cooperativa e voluntária.

No mais, considerando que na mediação não há regras de evidência ou noções legalistas de relevância, decisões supostamente se embasarão mais pelo contexto do que por princípios abstratos. Por fim, pelo menos em teoria, emoções são reconhecidas e incorporadas no processo da mediação (GRILLO, 1991, p. 1.548).

Os mencionados aspectos da mediação são os responsáveis por ser esse método caracterizado, por muitos, como uma alternativa feminista às mazelas do patriarcado, tão presentes no sistema contencioso tradicional. Contudo, Grillo desafia essa visão, buscando, justamente, analisar os pontos negativos e positivos do método, através 
da observação, para então concluir se ele pode ser considerado ou não um avanço para as mulheres.

\subsection{A lei informal da mediação}

Nessa toada, quanto aos possíveis defeitos, comenta sobre "a lei informal da mediação", explicando que há uma série de expectativas em relação à maneira adequada de as partes agirem, sendo qualquer desvio inadequado e passível de punição (GRILLO, 1991).

Esta punição, vale dizer, é justamente o fato que distingue tal situação das meras normas sociais. ${ }^{18}$ Mesmo que, sob um olhar superficial, essa punição possa parecer trivial, pois costuma ser aplicada por meio de atos corriqueiros (como uma demissão ou uma risada), ela produz os efeitos esperados.

Diante disso, Grillo se debruça sobre o conceito de configurações microssociais, ${ }^{19}$ encontrado na obra Reisman (1983), esclarecendo tratar-se de uma situação decorrente da interação de um pequeno grupo de pessoas, como resultado de sua proximidade física ou social, em que é possível observar justamente a existência de componentes normativos informais, geralmente não positivados ou percebidos conscientemente. Assim, o contexto das mediações poderia ser considerado como uma configuração microssocial.

Nas sessões observadas, restou evidente que a "lei informal da mediação" encontra grande amparo na análise do Termo de Audiência que será realizada pelo magistrado e, eventualmente, pelo Ministério Público. Ocorre que os facilitadores se utilizam dessa situação para conduzir a sessão de modo que esta não resulte em algo muito absurdo. Por um lado, é de fato necessário que haja uma conformidade estrita com a lei, principalmente quando há interesses de menores envolvidos. Por outro lado, é muito difícil delimitar até que ponto pode ocorrer essa interferência pelo facilitador em prol do sustento da legalidade.

06/04/2018: Mediadora explica a um casal que, quando os mediadores dizem "desse jeito não pode", é porque eles têm experiência e sabem que não vai passar.

Em verdade, é justamente papel do Ministério Público e do magistrado a realização desse controle da legalidade. Contudo, no trabalho de campo realizado, ficou evidente que esse cenário é utilizado pelo facilitador como meio de condução da sessão. Ocorre que a lei informal da mediação se utiliza das microssanções para encorajar as

\footnotetext{
18 Nas palavras da autora: “...the mere 'shoulds' of daily conversation...” (GRILLO, 1991, p. 1.556).

19 Tradução nossa para "microsocial settings".
} 
partes a substituir práticas advindas do meio contencioso, tal qual a retórica da culpa, dos princípios abstratos, das normas rígidas, pelas práticas advindas das ADRs, tal qual a retórica do compromisso e do relacionamento.

16/05/2018: No momento de abertura da mediação, a mediadora diz que eles têm como norma que se deve "escutar sem interrupção", e que "o primeiro passo para o acordo dar certo é querer que dê certo".

Tal substituição é, de fato, muito coerente com a lógica da mediação, pois, além de estimular que as partes foquem naquilo que é importante apenas para elas na resolução daquele conflito, permite que pessoas das mais diversas culturas, religiões e variedades de estruturas familiares se apropriem do procedimento. Desse ponto de vista, o litígio poderia ser enquadrado como um conflito de caráter pessoal, em que não há o certo e o errado, verdade ou mentira, mas apenas duas diferentes visões de mundo (GRILLO, 1991, p. 1.560).

Contudo, salienta a professora, que, ao se negligenciar a discussão de determinados valores durante uma mediação, há o risco de obscurecer questões de poder social desigual e do papel desempenhado por cada um em função da socialização, ${ }^{20}$ já que essa negligência seria produto da concepção de que qualquer membro da família, independentemente de sua condição social, seria igualmente responsável por qualquer situação (GRILLO, 1991).

\subsection{A Desconsideração do Contexto}

Outra praxe advinda da lei informal da mediação, segundo a autora, é desconsiderar o contexto, sendo este o do passado dos mediandos ou o da sociedade como um todo.

Expressões recorrentes em sessões de mediação, tais quais "deixar o passado de lado", "não buscar culpados pelas situações", "focar apenas no futuro”, demonstram que o propósito pelo qual a mediação foi inicialmente inserida no procedimento de divórcio deixa de existir, qual seja, a consideração do contexto do conflito. Isso porque a desconsideração do passado de uma relação implica necessariamente na desconsideração do contexto (GRILLO, 1991, p. 1.563-1.564).

04/04/2018: Mediação entre um casal formado por um homem e uma mulher. No momento de se discutir a divisão dos bens, o casal entra em conflito sobre quem indenizaria

20 Sobre socialização, voltar à explicação feita no subtópico da Introdução. 


\begin{abstract}
o outro acerca de benfeitorias realizadas no imóvel em que eles residiram juntos.

Ao notar que as partes estavam discutindo muito, a mediadora tenta contornar a situação. Começa a falar como funciona a vida a dois, sobre a necessidade de se fazer concessões. Diz que "tem que pôr uma pedra no passado para chegar num acordo mútuo, deixar os conflitos de lado para pensar na criança”.
\end{abstract}

Além disso, suprimir o contexto do passado é tratar a todos como sujeitos neutros, como se o ponto de partida daquela relação fosse a sessão de mediação/ conciliação, como se o casal fosse igualmente presente e uma boa referência à criança eventualmente envolvida (GRILLO, 1991).

Ainda, é comum a desconsideração do contexto da sociedade, por exemplo, o fato de que mulheres e homens não são materialmente tratados como iguais no dia a dia, não recebem os mesmos salários, não têm as mesmas oportunidades de emprego, ainda mais quando as mulheres estão afastadas há anos do mercado de trabalho por conta das exigências de uma vida familiar patriarcal (GRILLO, 1991).

\begin{abstract}
04/05/2018: Mediação entre um casal formado por um homem e uma mulher, ambos idosos, acompanhados do filho adolescente.

A mulher começa a explicar à mediadora: "Há dez anos que peço o divórcio e ele nunca falou nada. Chegamos ao ponto de morar na mesma casa em quartos separados. Até que esse ano cheguei a meu limite e dei entrada no divórcio. Ele recebeu lá a intimação e não falou mais comigo, nem bom dia. Parecia uma pessoa transparente, sabe". Ainda, adiciona: "O que uma mulher espera de um marido? Não é carinho, amor e compreensão? Eu quero um homem que me valorize, me trate como ser humano. Como a esposa que lavou e passou por vinte e sete anos. Eu to [sic] me enterrando viva. Tudo na vida tem um limite. Acabou, acabou, acabou".
\end{abstract}

O homem deixava a mulher falar, sem intervir. No momento em que se discutia pensão - entre eles e para o filho - a mulher diz: "Eu não tenho acesso a nada, nada", e esfrega os dedos, para remeter ao símbolo do dinheiro. O homem se manifesta para dizer: "Não quero mais viver essa vida sem viver. Não quero continuar trabalhando em dois empregos".

Segundo Grillo (1991, p. 1.569), frequentemente os mediadores salientam a necessidade de as mulheres se tornarem economicamente independentes, sem levar em consideração as diferenças materiais entre a experiência masculina e feminina no mercado de trabalho. 
23/02/2018: Ao fim de uma mediação, no momento da leitura do Termo de Audiência, o mediador diz: "Eu coloquei por minha conta que vocês não vão querer pensão um do outro, vocês são jovens".

Assim, há um alinhamento irregular à lógica dos tribunais, pois os mediandos são tratados como sujeitos neutros e há uma desconsideração de contexto, mas dispensa-se a aplicação dos princípios abstratos e das normas rígidas. Ou seja, pode ser ainda mais perigoso, tendo em vista a informalidade do procedimento (GRILLO, 1991, p. 1.569).

\subsection{A supressão da raiva}

Uma forte crítica direcionada aos meios tradicionais de resolução de conflitos é a inexistência de um espaço para as subjetividades das partes se manifestarem, havendo um foco excessivo apenas no resultado da lide. Frente a isso, a mediação surge para muitos como uma promessa de trazer intuição e emoção para o procedimento, o que pode ser muito importante, principalmente na área de família, pois é comum que os "problemas reais" estejam obscurecidos pelas questões jurídicas, como se estas fossem o problema exclusivo ${ }^{21}$ (GRILLO, 1991, p. 1.572).

A autora defende, contudo, que essa promessa foi quebrada, pois, apesar de a mediação propiciar espaço para que sentimentos venham à tona, nem todos são aceitos. O maior exemplo disso é o abafamento do sentimento de raiva (GRILLO, 1991).

18/04/2018: Mediação entre um casal formado por um homem e uma mulher. No momento de se discutir a divisão dos bens, o casal entra em conflito sobre quem ficaria morando na casa. A mulher diz para o homem: "Quando você me conheceu, eu tinha tudo meu, minha casa e mobilias. A casa era pequena, mas era minha. Agora não quero separar para ter que pagar aluguel. As mobilias lá de casa são tudo as minhas porque eu sou cuidadosa". A mediadora interrompe a discussão, dizendo que eles deveriam "pensar na realidade", "com racionalidade".

O abafamento dos sentimentos, principalmente da raiva, resulta no impedimento de que a pessoa reconheça que ela possa ter sofrido algum tipo de dano. Essa

\footnotetext{
${ }^{21}$ A autora cita em nota de rodapé: GOLDBERG, Stephen B.; GREEN, Eric D.; SANDER, Frank E. A. Dispute resolution. 2. ed. Boston Little: Brown \& Co313, 1985. ("Family disputes are also well suited to alternative forums because the conflicts often involve a complex interplay of emotional and legal complaints"). Tradução nossa: Conflitos na área de família são também apropriados a serem resolvidos através de métodos alternativos de resolução de disputas porque geralmente envolvem uma interação complexa entre queixas legais e emocionais.
} 
linha de pensamento é apresentada por Trina Grillo com base no artigo intitulado "The Emergence And Transformation of Disputes: Naming, Blaming, Claiming...", ${ }^{22}$ escrito por William Felstiner, Richard Abel e Austin Sarat e publicado em 1981, no Jornal Law \& Society Review.

Felstiner, Abel e Sarat (1981) explicam que buscam estudar os conflitos mudando o foco, tradicionalmente presente nas instituições, para os indivíduos. Assim, estudam de que forma as disputas surgem e se transformam, sendo estas um processo social, o que significa dizer que elas dependerão do modo pelo qual o indivíduo percebe o eventual dano sofrido e responde ao sentimento de injustiça.

Sendo, portanto, um processo social, o surgimento e a transformação das disputas podem se dar em três diferentes etapas. A primeira delas é chamada pelos autores como Naming (nomeando), sendo esta o momento em que o indivíduo se vê capaz de dizer para si mesmo que determinada experiência foi a ele nociva, ou seja, é a compreensão do dano.

A segunda etapa é nomeada pelos autores como Blaming (culpando), sendo esta a transformação do dano em uma queixa, ou seja, ocorre quando o indivíduo atribui a responsabilidade de seu prejuízo a outra pessoa ou a uma entidade social (FELSTINER, 1981, p. 635). Para melhor elucidação, é uma situação que se encaixa no famigerado ditado popular "dar nome aos bois". A terceira etapa, por fim, é nomeada pelos autores como Claiming (reivindicando), que ocorre quando o indivíduo expressa sua queixa à pessoa ou entidade social considerada responsável e exige alguma solução.

Como essas etapas dependem, em grande parte, das subjetividades das pessoas - inclusive, os autores demonstram que pessoas com maior escolaridade têm maiores chances de reconhecerem um dano e reivindicarem seus direitos (FELSTINER, 1981, p. 635)-, dependerão também dos sentimentos dos indivíduos. Assim, principalmente a etapa Blaming, envolverá naturalmente sentimentos tais qual a raiva. Ora, essa é uma reação natural e esperada de uma pessoa ao notar que ela sofreu algum tipo de dano em função de outrem.

Grillo (1991) observa que, na mediação, é sufocada a etapa de Blaming, o que impediria o indivíduo de alcançar a etapa seguinte do processo, ou seja, reivindicar seus direitos (Claiming). Ainda, considerando que pessoas com menos acesso à informação e mais vulneráveis em geral na sociedade apresentam maior dificuldade em trilhar as três etapas, o sufocamento do sentimento de raiva - e de emoções em geral - coloca mais um obstáculo a essa população.

22 O surgimento e a transformação das disputas: nomeando, culpando e reivindicando (tradução nossa). 
A partir disso, Grillo (1991, p. 1.572-1.573, 1.576-1.579) defende que as mulheres que passam por um divórcio, principalmente aquelas que fazem parte de outras minorias (mulheres negras, pobres), ${ }^{23}$ podem estar especialmente suscetíveis a serem abaladas por um procedimento que as impede de manifestar seu sentimento de raiva.

Isso porque, considerando a socialização feminina, as mulheres são criadas e ensinadas a justamente não expressarem sua raiva, a serem sempre submissas e pacíficas, então não é comum que elas não consigam compreender esse sentimento, muito menos expressá-lo, o que, para Felstiner, Abel e Sarat (1981), colabora para que não haja a compreensão do dano e também o efetivo acesso à justiça.

Assim, a raiva ser negada, até mesmo em um espaço teoricamente seguro para que as emoções venham à tona, é extremamente violento e silenciador, principalmente para as pessoas que já sofrem com isso em seu dia a dia.

Vale mencionar, ainda, que é frequente ocorrer brigas fora das salas em que ocorrem as mediações/conciliações, as quais podem ser escutadas por todo o Centro, pois o local é pequeno. Ou seja, as manifestações explosivas de emoções são admitidas, mas apenas fora das salas em que ocorrem as sessões.

20/04/2018: Enquanto observava uma sessão, ouvia uma briga que acontecia na sala de espera. Duas mulheres gritavam. Lembrei que já ouvi os estagiários e mediadores falando que essas brigas são comuns. Pode ser que elas sejam tão comuns justamente porque não é dado o espaço necessário para as emoções fluírem durante as sessões.

\subsection{O terceiro que não é neutro}

Desconsiderar o contexto é também partir do pressuposto de que o facilitador é um terceiro neutro ou imparcial, concepção esta que é reproduzida como um dos princípios orientadores da mediação. Nesse sentido, vale mencionar o art. $166,{ }^{24}$ do

23 "For a woman who has just found her anger, anger which has enabled her to free herself from an oppressive relationship and involve herself and her family in a divorce proceeding, the suppression of the very force that has driven her forward is a devastating message": A supressão da raiva para uma mulher que tenha acabado de compreendê-la e, com isso, tenha se sentido capaz de se livrar de um relacionamento opressor e dar início ao procedimento de divórcio, é uma mensagem devastadora. (GRILLO, 1991, p. 1.576, tradução nossa).

24 Art. 166. A conciliação e a mediação são informadas pelos princípios da independência, da imparcialidade, da autonomia da vontade, da confidencialidade, da oralidade, da informalidade e da decisão informada. 
CPC, os arts. $1^{\text {o25 }}$ e $2^{\text {o26 }}$ da Lei n. 13.140/2015, bem como o art. $1^{\text {o27 }}$ da Resolução n. 125, do CNJ.

$\mathrm{O}$ inciso IV, do art. $1^{\circ}$, da Resolução n. 125, do CNJ chega a definir o que deve ser entendido por imparcialidade como “...o dever de agir com ausência de favoritismo, preferência ou preconceito, assegurando que valores e conceitos pessoais não interfiram no resultado do trabalho, compreendendo a realidade dos envolvidos no conflito e jamais aceitando qualquer espécie de favor ou presente".

Grillo defende que a imparcialidade, baseada na concepção de um observador sem uma perspectiva, é um mito. Ocorre que o mediador, assim como qualquer outra pessoa, necessariamente parte de sua perspectiva particular, possui seus próprios valores e pontos de vista (GRILLO, 1991, p. 1.587).

A autora aponta que a forma mais maligna pela qual a parcialidade do mediador pode ser observada é o preconceito, que se manifesta a favor ou contra uma pessoa em função de, por exemplo, sua raça, gênero ou classe (GRILLO, 1991, p. 1.587).

A autora defende ser saudável que a neutralidade, se não vista como um dogma intocável, sirva como aspiração, mesmo que jamais ela possa ser alcançada. Para tanto, forçoso, de início, assumir que as pessoas possuem suas concepções próprias, ou seja, não negar que a parcialidade existe. A partir disso, faz-se necessário criar alguns mecanismos que mitiguem as falhas naturais da imparcialidade (GRILLO, 1991, p. 1.587$1.588)$.

Acontece que, ao contrário do meio das ADRs, no meio contencioso já existem diversos mecanismos, geralmente resultantes da formalidade excessiva, que buscam fortalecer uma suposta imparcialidade, por exemplo: os juízes, em audiências, sentam distantes das partes, se comunicando com elas por meio de seus respectivos patronos; no mais, os juízes raramente falam com uma das partes individualmente e, caso o façam, são obrigados a comunicar a outra parte sobre o teor da conversa (GRILLO, 1991, p. 1.589).

Falar das ADRs, por sua vez, é falar justamente de um espaço em que grande parte desses mecanismos formais são postos de lado. Por isso, o mediador sentará

$25 \quad$ Art. $1^{\circ}$. Esta Lei dispõe sobre a mediação como meio de solução de controvérsias entre particulares e sobre a autocomposição de conflitos no âmbito da administração pública.

Parágrafo único. Considera-se mediação a atividade técnica exercida por terceiro imparcial sem poder decisório, que, escolhido ou aceito pelas partes, as auxilia e estimula a identificar ou desenvolver soluções consensuais para a controvérsia.

26 Art. $2^{\circ}$. A mediação será orientada pelos seguintes princípios:

I - Imparcialidade do mediador.

27 Art. $1^{\text {o }}$. - São princípios fundamentais que regem a atuação de conciliadores e mediadores judiciais: confidencialidade, decisão informada, competência, imparcialidade, independência e autonomia, respeito à ordem pública e às leis vigentes, empoderamento e validação. 
próximo das partes, falará diretamente com elas, mesmo com a presença de um advogado, e, quando necessário, recorrerá ao caucus (GRILLO, 1991, p. 1.589).

Percebe-se, assim, que, no meio contencioso, não há um apego cego à crença de uma neutralidade, tanto que diversos mecanismos são postos para mitigar uma possível aproximação entre o julgador e as partes. Isso não significa que é melhor que o meio das ADRs ou que este, por sua vez, apresenta um apego cego à crença da neutralidade. Tenta-se, em verdade, evidenciar que o meio das ADRs ainda é novo e, por isso, faltam mecanismos mais concretos de mitigação de uma potencial parcialidade, que não deve ser negada.

Necessário, ainda, considerar que, justamente pela lógica da informalidade que é colocada no meio das ADRs, há uma maior tendência de tanto as partes quanto os mediadores se sentirem mais à vontade, o que pode resultar em um ambiente mais fértil à exteriorização de preconceitos ${ }^{28}$ e em uma influência do ponto de vista do mediador no resultado da mediação.

\subsection{A aplicação da guarda compartilhada}

A Lei n. 11.698/2008 alterou os arts. 1.583 e 1.584 do Código Civil (CC) brasileiro, a fim de instituir e disciplinar a guarda compartilhada. Com isso, o art. 1.583, $\S 1^{\circ}$, do Código Civil, passa a definir guarda compartilhada como “... a responsabilização conjunta e o exercício de direitos e deveres do pai e da mãe que não vivam sob o mesmo teto, concernentes ao poder familiar dos filhos comuns".

Foge ao escopo desse trabalho aprofundar-se acerca do instituto da guarda compartilhada, dos pontos positivos e negativos levantados em debate doutrinário. Contudo, a questão da sua aplicação em mediações/conciliações de divórcio ocorridas no CEJUSC Vergueiro evidenciou-se em trabalho de campo. Somado a isso, Grillo (1991) explora essa questão em seu artigo. Desse modo, levantar-se-á uma breve discussão sobre esse ponto.

Das quinze mediações acompanhadas neste trabalho de campo, quatorze resultaram em guarda compartilhada. Das quatorze, em apenas duas a residência foi fixada com o pai, sendo que, em uma dessas, foi por uma razão estratégica, qual seja, com o término do relacionamento, a mulher havia saído da casa que compartilhara com o homem, não tendo ainda um endereço fixo. Para que o Ministério Público ou o juiz não

\footnotetext{
28 "Richard Delgado and his coauthors have shown that people who hold prejudicial attitudes are most prone to act on those attitudes in an intimate setting". Richard Delgado e coautores demonstraram que pessoas preconceituosas tendem a demonstrar isso em espaços mais íntimos. (GRILLO, 1991, p. 1.589-1.590, tradução nossa).
} 
impugnassem o fato de que não teria um endereço fixo apontado no Termo de Audiência, as partes e a mediadora chegaram a essa solução.

Tornou-se nítido em trabalho de campo que a praxe tem sido a aplicação da guarda compartilhada, não obstante fique evidente que os mediandos não confiam um no outro, ou têm dificuldade de comunicação. ${ }^{29}$

18/04/2018: Mediação entre um casal formado por um homem e uma mulher, com uma filha, ainda menor. $\mathrm{O}$ homem havia procurado a Defensoria Pública e a mulher estava acompanhada de advogada. A sessão foi longa e muito tensa. $\mathrm{O}$ casal entrou em intenso conflito no momento de divisão de bens, apenas.

A advogada da mulher se antecipa em relação à mediadora e passa a explicar sobre guarda compartilhada, como se ela já tivesse conversado com sua cliente sobre o assunto.

O homem concorda com a aplicação da guarda compartilhada, com a residência fixa na casa da mãe. Contudo, tece alguns comentários, que evidenciam as enormes dificuldades de relacionamento entre o homem e a mulher, bem como o quanto ele atribui à mãe a responsabilidade pela criação da criança: "Ela tem algumas atitudes que não são de papel de mãe"; "Queria pedir um bom senso da mãe para ela por um pouco mais de dinâmica, atividade para a menina". Quando a mãe e sua advogada já haviam se retirado da sala, o homem se dirige à mediadora e questiona como poderia agir caso verificasse que a menina estivesse sofrendo maus tratos.

Aparentemente, considerando que os casais que para o CEJUSC são encaminhados não buscam um divórcio litigioso, presume-se que há uma relação continuada estável, ou com potencial para tal. Contudo, nem sempre esse cenário é o verdadeiro.

Ocorre que as partes chegam às sessões sem o conhecimento jurídico suficiente das questões. Assim, cabe ao facilitador, ou ao eventual advogado que acompanhe as partes, esclarecer-lhes acerca das questões jurídicas. Porém, nem sempre isso ocorre da melhor forma possível, sendo comum os mediadores/conciliadores suporem que o casal busca uma guarda compartilhada, e as partes não rebaterem.

Vale mencionar, inclusive, que o Código de Ética de Conciliadores e Mediadores Judiciais apresenta, em seu art. $1^{\text {o }}$, II, que um dos princípios fundamentais que regem a atuação destes profissionais é o da decisão informada, sendo este princípio

29 Vale esclarecer que este trabalho não tem pretensões generalizadoras. Realizou-se investigação social antropológica, com limitação temporal. Assim, o resultado apontado não é suficiente para se chegar a um diagnóstico concreto, apenas chama a atenção para a questão ora debatida. 
definido como o "dever de manter o jurisdicionado plenamente informado quanto aos seus direitos e ao contexto fático no qual está inserido". Assim, é dever dos mediadores e conciliadores judiciais apresentarem todas as possibilidades jurídicas quanto à questão da guarda dos filhos menores, a fim de que as partes possam fazer escolhas respaldadas em informações.

Sobre a questão da aplicação da guarda compartilhada, Grillo (1991) sustenta que a noção de igualdade é usada com eficiência apenas para tirar o controle, tradicionalmente das mulheres, sobre as crianças, e compartilhá-lo com os homens, independentemente de como era sua relação com a criança antes da estipulação da guarda (GRILLO, 1991).

04/04/2018: Mediação entre um casal formado por um homem e uma mulher. No momento de discussão acerca da fixação da pensão alimentícia para o filho menor, o homem passa a negociar com a mediadora qual porcentagem incidiria sobre seu salário a fim de descontar para a pensão. Fala para a mediadora "bater o martelo" ao consensuarem em $22 \%$ sobre o seu salário, e $21 \%$ sobre o salário mínimo em caso de desemprego.

Em meio a uma discussão, a mulher diz que o homem já havia expulsado ela da casa em que eles viviam juntos, oferecendo dinheiro em troca. Ainda, fala que ele já havia ameaçado ficar desempregado apenas para pagar uma quantia menor referente à pensão alimentícia para o filho. O homem responde dizendo: "ameaça acontece mesmo".

Ao fim da sessão, decidiu-se pela guarda compartilhada, sendo a residência fixada com a mãe.

Ocorre que tal eficiência não se nota na mesma proporção quando se exige que os homens assumam uma responsabilidade por seus filhos que eles não querem assumir. Nestes casos, o pagamento da pensão alimentícia à criança, quando existente, acaba servindo ao pai como representativo de seu envolvimento na criação.

Segundo a autora, raramente se ouve dizer que o modelo da guarda compartilhada está sendo usado como meio de determinar que o pai participe na criação de seu filho, mesmo que seja este o desejo de muitas mães (GRILLO, 1991, p. 1.570).

Em verdade, o modelo da guarda compartilhada, ao partir da noção de igualdade, acaba por reproduzir privilégios geralmente concedidos a pais, sendo estes decorrentes de uma perturbação que é criada na vida da mãe, que se torna instável, pois há uma presunção de que as mães estarão sempre disponíveis para cuidar física e emocionalmente de seus filhos (GRILLO, 1991).

Grillo sustenta ainda que os mediadores são pessoas comuns, que vivem em uma sociedade patriarcal, portanto também suscetíveis a presumir que os compromissos das mulheres com seus trabalhos são secundários em relação aos dos homens. Com isso, 
em uma mediação, as mães acabam por ser encorajadas a assimilarem a noção de que possuem a responsabilidade primária sobre a criança, a não pensar em si mesmas como arquétipo de trabalhadoras (GRILLO, 1991).

06/04/2018: Mediação entre um casal formado por um homem e uma mulher. No momento de discussão acerca da guarda, o homem diz: "A menina tem que ficar com a mãe, a não ser que ela seja muito relaxada. Eu não ia tirar ela da mãe, porque é uma boa mãe".

Grillo afirma que, mesmo que a guarda seja estipulada como compartilhada, é comum que, na prática, apenas um dos pais, geralmente a mulher, é quem realmente cuida da criança. Assim, mesmo que materialmente o exercício da guarda funcione como unilateral, na teoria ela é compartilhada, e carrega consigo o ônus de um dos genitores estar submetido a certo controle do outro (GRILLO, 1991).

Nesse sentido, ficou claro no trabalho de campo que a praxe é estipular guarda compartilhada, mas com a residência fixada com a mulher, ou seja, permanece sendo a mulher a pessoa incumbida das maiores responsabilidades, mas se soma a isso os ônus de ter que abrir espaço para intervenção do outro genitor em sua vida, como reflexo da interferência na vida da criança.

Conclusões

Conclui, por este trabalho, que a mediação judicial obrigatória ocorrida em CEJUSC, da forma como está colocada atualmente, não se mostra como uma alternativa melhor em relação ao método tradicional de resolução de conflito, ou seja, a via judicial propriamente dita.

A primeira e grande questão encontra-se na obrigatoriedade da mediação. Como já dito, para que os métodos alternativos de resolução de disputas funcionem da forma que se propõem, o requisito primário é a voluntariedade de ambas as partes.

$\mathrm{O}$ que se nota atualmente é que, geralmente, as partes que consentem com a mediação judicial em CEJUSC normalmente são movidas por motivos secundários, tais quais a maior agilidade e os menores custos. As partes dificilmente chegam informadas sobre o que realmente se trata a mediação, quais as propostas, o que as esperam. Elas apenas descobrem quando a sessão já se inicia. Desse modo, não se pode dizer que as partes tomaram, efetivamente, uma decisão informada acerca do método.

Outra questão é a informalidade das mediações/conciliações, a qual torna a figura do facilitador imensamente impactante, o que pode ser muito ruim ao se considerar que a neutralidade, na prática, é um mito, e que os facilitadores possuem diferentes visões de mundo, carregam preconceitos, etc. 
A informalidade, por si só, não é o problema. Em verdade, ela é, de fato, essencial para o deslinde correto de uma mediação ou conciliação. Ainda, pode ser vista como um avanço, pois aproxima o Direito do povo, ou seja, de quem a ele pertence.

Contudo, a dificuldade se coloca quando a informalidade sobressai em um método que não tem cumprido com suas promessas, já que se nota uma adoção indevida de práticas advindas dos meios tradicionais de resolução de conflitos, adoção esta manifestada primordialmente por meio da "lei informal da mediação". Ou seja, existem normas invisíveis aplicadas por facilitadores que não são neutros, sem critérios objetivos e sem distanciamento.

Diante desse cenário, mais uma vez, a população que é mais prejudicada é a mais vulnerável, ou seja, é a população que tem pouco acesso à informação, principalmente no que diz respeito aos seus direitos. São as minorias políticas, atingidas por todo o preconceito presente na sociedade.

Nesse sentido, e principalmente em sessões de mediação na área de família (no caso, de divórcio), a figura da mulher destaca-se. Isso porque, em função da sociedade patriarcal hoje colocada, a mulher era categoria social alijada inclusive das funções produtivas, sendo restrita aos cuidados dos lares dos homens - maridos, patrões, senhores de engenho...

Quando assimiladas ao sistema produtivo, ou seja, quando se tornou admissível à sociedade patriarcal capitalista que a mulher trabalhasse dentro do sistema produtivo, recebendo um salário por isso, elas se tornaram, na verdade, mera ferramenta de produção de maior lucro, sofrendo ainda maior exploração. Não bastando, não foram desoneradas da responsabilidade pelos cuidados dos lares dos homens, arcando com duplas, triplas jornadas.

Os estereótipos de gênero, nesse contexto, atuam como ferramenta necessária à manutenção dessa desigualdade posta entre homens e mulheres, que permite a potencialização da geração de lucro para o capitalista.

Assim, é interessante ao capital que se mantenha a ideia de que a mulher deve se casar com um homem e ter filhos; deve ser a pessoa que será sempre a principal responsável pelos cuidados com o marido e filhos - inclusive encarregada do trabalho emocional; deve trabalhar no lar e dentro do sistema produtivo, de forma assalariada, para "complementar" a renda familiar e não precisar de eventual pensão alimentícia do excônjuge; deve aceitar que o ex-cônjuge intervenha em sua vida pessoal com a prerrogativa de acompanhar a vida dos filhos; deve ser resiliente para manter vivo o casamento, colocando uma pedra sobre seu passado e suas emoções, e seguindo em frente.

Apesar do cenário apresentado, e assim como Grillo, o que moveu a escolha pelo tema deste trabalho foi o grande interesse despertado pelos métodos alternativos de resolução de conflitos e as potencialidades neles observadas. 
As ADRs surgem com o potencial de propagar outra forma de comunicação, uma outra cultura. Surge oferecendo a possibilidade de diminuir a reificação imposta sobre as pessoas, aumentar a capacidade de se refletir sobre o que se é, o que se pensa, o que se sente. Ou seja, surge como uma promessa de instrumento capaz de tornar um pouco menos distante o acesso à justiça efetivo, a democracia efetiva.

A criação teórica das ADRs se mantém, porém, atualmente, a prática mostrase assimilada por objetivos alheios, e alinhados aos interesses do capital, tal qual a maior celeridade no Judiciário (limpar as prateleiras dos juízes retirando os "casos fáceis") e os menores custos para o Estado (mediadores/conciliadores que ainda não são assalariados, pouca estrutura física, menor dispêndio financeiro com Defensores Públicos, etc.).

Nesse sentido, vale lembrar as motivações da Resolução n. 125/2010, do Conselho Nacional de Justiça, sendo algumas delas a busca por eficiência operacional e redução de excessiva judicialização de conflitos de interesses. Assim, há uma deturpação desses métodos, o que acaba prejudicando, principalmente, a população mais vulnerável.

Ainda, sobre essa lógica que hoje é colocada, há um incentivo para que as sessões sejam conduzidas no menor tempo possível. Com isso, todos os casos são tratados como "fáceis", as emoções são suprimidas para economizar tempo, os pontos a serem discutidos são tratados como mera formalidade, pouca informação é transmitida, pouca comunicação é estimulada, estereótipos de gênero são mantidos e impactam na condução das sessões e, portanto, em seus resultados.

Nesse sentido, vale reproduzir as seguintes anotações que se fez no Caderno de Campo:

06/04/2018: Hoje ficou muito perceptível que, como as sessões envolvem os mesmos pontos (divórcio, nome, guarda, visitas, pensão, bem), os mediadores começam a agir no automático e focam em contemplar todos os pontos e só. Não vão além, abafam as discussões, não entram na intimidade e, às vezes, até esquecem-se de alguns desses pontos e decidem por conta (ex: pensão entre os cônjuges).

16/05/2018: A verdade é que a mediação é assumidamente utilizada como modo de impedir que casos ditos como fáceis cheguem às prateleiras do Judiciário. Problema é que: o que é um caso fácil? Bom é que, de fato, é uma mudança de cultura, as partes podem falar e já resolver na hora. Só que o excesso de litigância presente na nossa cultura não vai ser combatido com isso, não vai até a raiz.

Assim, nota-se que as ADRs estão ganhando força dentro do Direito, mas com os propósitos errados, o que certamente atingirá - e está atingindo - primordialmente a população mais vulnerável. Não obstante, a mediação/conciliação realmente voluntária, 
e conduzida da forma correta, apresenta enorme potencial de promoção de uma nova sociedade, em que exista um efetivo acesso à justiça.

São Paulo, novembro de 2018.

\section{Referências}

ASPERTI, Maria Cecília de Araujo. Acesso à justiça e estereótipos de gênero no judiciário: o caso propaganda "Musa do Verão 2006". In: BERTOLIN, Patrícia Tuma Martins; ANDRADE, Denise Almeida de; MACHADO, Monica Sapucaia. (org.). Mulher, sociedade e vulnerabilidade. 1. ed. Erechim: Deviant, 2017. p. 99-118.

ASPERTI, Maria Cecília de Araujo. Meios consensuais de resolução de disputas repetitivas: a conciliação, a mediação e os grandes litigantes do judiciário. 2014. Dissertação (Mestrado em Direito Processual) - Faculdade de Direito, Universidade de São Paulo, São Paulo, 2014.

BRASIL. Conselho Nacional de Justiça. Resolução n. 125, de 29 de novembro de 2010. Brasília, DF, nov. 2010. Disponível em: http://www.cnj.jus.br/images/stories/docs_cnj/resolucao/arquivo_ integral_republicacao_resolucao_n_125.pdf. Acesso em: 5 fev. 2018.

BRASIL. Lei n. 11.698, de 13 de junho de 2008. Altera os arts. 1.583 e 1.584 da Lei n. 10.406, de 10 de janeiro de 2002 - Código Civil, para instituir e disciplinar a guarda compartilhada. Portal do Planalto, Brasília, DF., jun. 2018. Disponível em: http://www.planalto.gov.br/ccivil_03/_Ato20072010/2008/Lei/L11698.htm. Acesso em: 6 set. 2018.

BRASIL. Lei n. 13.105, de 16 de março de 2015. Código de Processo Civil. Portal do Planalto, Brasília, DF., mar. 2015. Disponível em: http://www.planalto.gov.br/ccivil_03/_ato2015-2018/2015/ lei/113105.htm. Acesso em: 5 fev. 2018.

BRASIL. Lei n. 13.140, de 26 de junho de 2015. Dispõe sobre a mediação entre particulares como meio de solução de controvérsias e sobre a autocomposição de conflitos no âmbito da administração pública; altera a Lei n. 9.469, de 10 de julho de 1997, e o Decreto n. 70.235, de 6 de março de 1972; e revoga o $\S 2^{\circ}$ do art. $6^{\circ}$ da Lei n. 9.469, de 10 de julho de 1997. Portal do Planalto, Brasília, DF., jun. 2015. Disponível em: http://www.planalto.gov.br/ccivil_03/_ato2015-2018/2015/lei/L13140. htm. Acesso em: 5 fev. 2018.

CAPPELLETTI, Mauro. Os métodos alternativos de solução de conflitos no quadro do movimento universal de acesso à justiça. Revista de Processo, São Paulo, v. 19, n. 74, p. 82-97, abr./jun. 1994.

CAPPELLETTI, Mauro; GARTH, Bryant G. Acesso à justiça. Tradução e revisão Ellen Gracie Northfleet. Porto Alegre: Sergio Antonio Fabris, 1988.

CAVA, Anita. Taking judicial notice of sexual stereotyping. Arkansas Law Review, Fayetteville, v. 43, n. 1, p. 27-56, 1990. 
CHIESA, Carolina Dalla; FANTINEL, Letícia Dias. "Quando eu vi, eu tinha feito uma etnografia": notas sobre como não fazer uma "etnografia acidental". In: ENCONTRO DE ESTUDOS ORGANIZACIONAIS DAANPAD, 8., 2014, Gramado. Anais [...]. Gramado: [s. n.], 2014. p. 1-16. Disponível em: http://www.anpad.org.br/admin/pdf/2014_EnEO48.pdf. Acesso em: 6 abr. 2019.

COSTA, Susana Henriques da. Acesso à justiça: promessa ou realidade? Uma análise do litígio sobre creche e pré-escola no município de São Paulo. In: GRINOVER, Ada Pellegrini; WATANABE, Kazuo; COSTA, Susana Henriques da. (coord.). O processo para solução de conflitos de interesse público. Salvador: Juspodivm, 2017. p. 449-473.

DELPHY, Christine. Patriarcado (teorias do). In: HIRATA, Helena et al (org). Dicionário crítico do feminismo. São Paulo: Unesp, 2009.

ESTEREÓTIPO. In: MICHAELIS: dicionário brasileiro da língua brasileira. São Paulo: Melhoramentos. Disponível em: https://michaelis.uol.com.br/moderno-portugues/busca/portuguesbrasileiro/estere\%C3\%B3tipo/. Acesso em: 1 ago. 2018.

FELSTINER, William L. F.; ABEL Richard L.; SARAT, Austin. The emergence and transformation of disputes: naming, blaming, claiming... Law \& Society Review, Malden, MA, v. 15, n. 3-4, p. 631-654, 1981.

FISS, Owen M. ADR: second-class justice? Connecticut Law Tribune, Fairfield, CT, v. 12, n. 11, p. 1-17, Mar. 1986.

FISS, Owen M. Um novo processo civil: estudos norte-americanos sobre jurisdição, constituição e sociedade. Coordenação da tradução Carlos Alberto de Salles; Tradução Daniel Porto Godinho da Silva e Melina de Medeiros Rós. São Paulo: RT, 2004. p. 121-145.

GABBAY, Daniela Monteiro; ASPERTI, Maria Cecília de Araújo; COSTA, Susana Henriques da. Are the haves getting even more ahead than ever? Reflections on the political choices concerning access to justice in Brazil in the search of a new agenda. FGV Direito SP Research Paper Series, São Paulo, n. 158, p. 1-23, jul. 2017. Disponível em: https://papers.ssrn.com/sol3/papers.cfm?abstract_ $\mathrm{id}=2998779$. Acesso em: 6 fev. 2018.

GALANTER, Marc. Acesso à justiça em um mundo de capacidade social em expansão. Tradução: João Eberhardt Francisco, Maria Cecília de Araújo Asperti e Susana Henriques da Costa. Revista Brasileira de Sociologia do Direito, Porto Alegre, v. 2, n. 1, p. 37-49, jan./abr. 2015.

GALANTER, Marc. Por que "quem tem” sai na frente: especulações sobre os limites da transformação no direito. Organização e tradução, Ana Carolina Chasin. São Paulo: FGV Direito SP, 2018. Título original: Why The 'Haves' Come Out Ahead: Speculations on the Limits of Legal Change.

GOMES, Janaína Dantas Germano. Cartórios judiciais e o acesso à justiça: tensões e disputas. 2014. Dissertação (Mestrado) - Faculdade de Direito, Universidade de São Paulo, São Paulo, 2014. 
GRILLO, Trina. The mediation alternative: process dangers for women. Yale Law Journal, New Haven, v. 100, n. 6, p. 1.545-1.610, 1991.

GRINOVER, Ada Pelegrini. Os métodos consensuais de solução de conflitos no novo CPC. In: GRINOVER, Ada Pelegrini et al. O novo Código de processo civil: questões controvertidas. São Paulo: Atlas, 2015. p. 1-21.

GRINOVER, Ada Pellegrini; SADEK Maria Tereza; WATANABE Kazuo; GABBAY, Daniela Monteiro; CUNHA, Luciana Gross. Estudo qualitativo sobre boas práticas em mediação no Brasil. Brasília, DF: Ministério da Justiça, 2014. Disponível em: http://mediacao.fgv.br/wp-content/ uploads/2015/11/Estudo-qualitativo-sobre-boas-praticas-em-mediacao-no-Brasil.pdf.

HILLESHEIM, Jaime. Conciliação trabalhista: ofensiva sobre os direitos dos trabalhadores na periferia do capitalismo. Rio de Janeiro: Lumen Juris, 2016.

HÜMMELGEN, Isabela; CANGUSSÚ, Kauan Juliano. Estereótipos de gênero no direito das famílias: um estudo da doutrina jurídica sobre alienação parental. In: ENCONTRO NACIONAL DE ANTROPOLOGIA DO DIREITO (ENADIR), 5., 2017, São Paulo. Anais [...]. Disponível em: http://www.enadir2017.sinteseeventos.com.br/simposio/view?ID_SIMPOSIO=28. Acesso em: 8 jul. 2018.

JUNQUEIRA, Eliane Botelho. Acesso à justiça: um olhar retrospectivo. Revista Estudos Históricos, Rio de Janeiro, v. 9, n. 18, p. 389-402, jul./dez. 1996.

KANT DE LIMA, Roberto. Por uma antropologia do Direito no Brasil. In: FALCÃO, Joaquim de Arruda (org.). Pesquisa cientifica e direito. Recife: Massangana, 1983. p. 89-116.

KANT DE LIMA, Roberto; BAPTISTA, Bárbara Gomes Lupetti. O desafio de realizar pesquisa empírica no Direito: uma contribuição antropológica. In: ENCONTRO DA ASSOCIAÇÃO BRASILEIRA DE CIÊNCIA POLITICA, 7., 2010, Recife. Anais [...]. Recife: ABCP, [2010?].

LEE, Joel. The evolving “A” in ADR. Kluwer mediation blog, [s. l.], Mar. 2012. Disponível em: http://mediationblog.kluwerarbitration.com/2012/03/14/the-evolving-a-in-adr/. Acesso em: 8 maio 2018.

LIMA, Juliana Domingos de. O que é 'trabalho emocional'. E como ele sobrecarrega as mulheres. Nexo Jornal, São Paulo, maio 2018. Disponível em: https://www.nexojornal.com.br/ expresso/2018/05/01/O-que-é-'trabalho-emocional'.-E-como-ele-sobrecarrega-as-mulheres?utm_ campaign=Echobox\&utm_medium $=$ Social\&utm_source $=$ Facebook\#link_time $=1525214735$. Acesso em: 21 maio 2018.

MELLO, Kátia Sento Sé; BAPTISTA, Bárbara Gomes Lupetti. Mediação e conciliação no judiciário: dilemas e significados. Dilemas: Revista de Estudos de Conflito e Controle Social, Rio de Janeiro, v. 4, n. 1, p. 97-122, mar. 2011. Disponível em: https://revistas.ufrj.br/index.php/dilemas/article/ view/7208/5801. Acesso em: 2 fev. 2018. 
MENDES, Aluisio Gonçalves de Castro; SILVA, Larissa Clare Pochmann da. Acesso à justiça: uma releitura da obra de Mauro Cappelletti e Bryant Garth, a partir do Brasil, após 40 anos. Revista Quaestio Iuris, Rio de Janeiro, v. 8, n. 3, p. 1.827-1.858, 2015. Disponível em: http://www.epublicacoes.uerj.br/index.php/quaestioiuris/article/view/19385. Acesso em: 6 fev. 2018.

MENKEL-MEADOW, Carrie. Dispute resolution: the periphery becomes the core. Judicature, California, v. 69, n. 5, p. 300-304, Feb./Mar. 1986.

MENKEL-MEADOW, Carrie. Ethics in alternative dispute resolution: new issues, no answers from the adversary conception of lawyers' responsibilities. South Texas Law Review, Houston, v. 38, n. 2, p. 407-454, May 1997. Disponível em: https://scholarship.law.georgetown.edu/cgi/viewcontent.cgi ?article $=2758 \&$ context $=$ facpub. Acesso em: 26 mar. 2018.

MENKEL-MEADOW, Carrie. The limits of adversarial ethics. In: RHODE, Deborah L. (ed.) Ethics in practice: lawyers' roles, responsibilities, and regulation. Oxford, NY: Oxford University Press, 2000. p. 123-144.

NAVES, Márcio Bilharinho. Prefácio à edição brasileira. In: PACHUKANIS, Evgeni. A teoria geral do direito e o marxismo e ensaios escolhidos (1921 - 1929). Tradução de Lucas Simone. São Paulo: Sundermann, 2017.

OSTIA, Paulo Henrique Raiol. Conciliação e acesso à justiça: um estudo qualitativo dos centros judiciários de solução de conflitos e cidadania. 2018. Tese (Doutorado) - Faculdade de Direito, Universidade de São Paulo, São Paulo, 2018.

PANDJIARJIAN, V. Os estereótipos de gênero nos processos judiciais e a violência contra a mulher na legislação. [S. l.: s. n.], [2003?]. Disponível em: http://www.tjmt.jus.br/INTRANET.ARQ/CMS/ GrupoPaginas/59/459/file/estereotipos_Genero_Valeria_Pandjiarjian.doc. Acesso em: 01/09/2018

PERET, Eduardo. Mulher estuda mais, trabalha mais e ganha menos do que o homem. Agência IBGE Noticias, Brasília, mar. 2018. Disponível em: https://agenciadenoticias.ibge.gov.br/agencianoticias/2012-agencia-de-noticias/noticias/20234-mulher-estuda-mais-trabalha-mais-e-ganhamenos-do-que-o-homem.html. Acesso em: 14 jul. 2018.

QUIVY, Raymond; CAMPENHOUDT, Luc Van. Manual de Investigação em ciências sociais. 4. ed. Lisboa: Gradiva, 2005.

REISMAN, William Michael. Looking, staring and glaring: microlegal systems and public order. Denver Journal of International Law \& Policy, Denver, v. 12, n. 2-3, p. 165-182, 1983. Disponível em: https://digitalcommons.law.yale.edu/cgi/viewcontent.cgi?article=1725\&context=fss_papers.

SAFFIOTI, Heleieth. A mulher na sociedade de classe: mito e realidade. 3. ed. São Paulo: Expressão Popular, 2013. 
SÃO PAULO (Estado). Centros Judiciários de Solução de Conflitos e Cidadania. Núcleo Permanente de Métodos Consensuais de Solução de Conflitos. Apostila de procedimentos e sistema SAJ: curso prático. Versão jan./2017. São Paulo: CEJUSC, 2017. Disponível em: http://www.tjsp.jus.br/ Download/Conciliacao/Nucleo/ApostilaCEJUSC-NPMCSC.pdf. Acesso em: 14 set. 2018.

SUPREMA Corte dos EUA aprova o casamento gay em todo o país. G1, São Paulo, jun. 2015. Disponível em: http://g1.globo.com/mundo/noticia/2015/06/suprema-corte-dos-eua-aprova-ocasamento-gay-nacionalmente.html. Acesso em: 23 maio 2018.

TARTUCE, Fernanda. Mediação no novo CPC: questionamentos reflexivos. In: FREIRE, Alexadre et al. (org.). Novas tendências do processo civil: estudos sobre o projeto do novo Código de Processo Civil. Slavador: Juspodivm, 2014. Disponível em: http:/www.fernandatartuce.com.br/wp-content/ uploads/2016/02/Media\%C3\%A7\%C3\%A3o-no-novo-CPC-Tartuce.pdf. Acesso em: 11 ago. 2018. 
